\title{
Negative- and positive-ion fragmentation of core-excited formic-acid molecules studied with three- and four-ion coincidence spectroscopy
}

\author{
Christian Stråhlman* \\ Malmö University, 20506 Malmö, Sweden; \\ Institute Methods and Instrumentation for Synchrotron Radiation Research, Helmholtz-Zentrum Berlin für Materialien und \\ Energie GmbH, Albert-Einstein-Strasse 15, 12489 Berlin, Germany \\ and MAX IV Laboratory, Lund University, P.O. Box 118, 22100 Lund, Sweden \\ Antti Kivimäki \\ Nano and Molecular Systems Research Unit, University of Oulu, P.O. Box 3000, 90014 Oulu, Finland \\ and MAX IV Laboratory, Lund University, P.O. Box 118, 22100 Lund, Sweden \\ Robert Richter \\ Elettra-Sincrotrone Trieste, Area Science Park, 34149 Trieste, Italy \\ Rami Sankari \\ MAX IV Laboratory, Lund University, P.O. Box 118, 22100 Lund, Sweden \\ (Received 20 February 2017; revised manuscript received 18 July 2017; published 8 August 2017)
}

\begin{abstract}
The negative-ion fragmentation of formic acid $(\mathrm{HCOOH})$ is studied with negative- and positive-ion coincidence spectroscopy. We report four-body ionic fragmentation where up to three positive ions are collected in coincidence with one negative ion. We report yields for 21 three-body channels and five four-body channels. More than $80 \%$ of all negative-ion fragmentation involves production of $\mathrm{O}^{-}$, and it is dominated by complete dissociation of all molecular bonds. Negative-ion creation is most abundant at high-Rydberg resonances and just above the molecule's core-ionization potentials. The existence of four-body fragmentation channels evidences a strong charge redistribution in the molecule.
\end{abstract}

DOI: 10.1103/PhysRevA.96.023409

\section{INTRODUCTION}

Formic acid $(\mathrm{HCOOH})$, the simplest of the carboxylic acids, attracts continuous attention from researchers due to its importance in many fields of astronomy, biology, chemistry, and physics. Formic acid in low concentration is almost omnipresent in Earth's troposphere, as gas or dissolved in natural sources such as rain water [1]. Emission of formic acid comes from both anthropogenic and biogenic sources. In chemical engineering, the synthesis of formic acid from $\mathrm{CO}_{2}$ is extensively studied [2]. The growing need for efficient energy storage suggests its increased use in fuel cells, combining easy storage in a liquid phase with high-energy density [3,4]. Formic acid has been suggested as a suitable product in carbon-capture reactions, where $\mathrm{CO}_{2}$ is captured either directly from the atmosphere or from high-concentration industry sources, and catalyzed to useful chemicals [5].

Beyond our planet, the formic-acid molecule is present in varying concentrations in stellar atmospheres; it has been discussed whether it is a precursor in the formation of amino acids, such as glycine, in space [6]. The natural abundance of $\mathrm{x}$-ray radiation in stellar environments has been a prominent reason for earth-based investigations of photochemical reactions following core-level excitation.

$\mathrm{X}$-ray excitation of molecules induces electronic processes which lead to fragmentation of the molecule. Core-excited and core-ionized states (i.e., excitation of a core electron to

\footnotetext{
*christian.strahlman@mah.se
}

an unoccupied orbital and to the continuum, respectively) of molecules containing low-Z atoms typically decay by emission of an Auger electron on a fs time scale. Further ionization can occur if the molecule holds excess energy after Auger decay. The decay of a core-excited or -ionized molecule by emission of an x-ray photon is less probable. The resulting dissociation of decaying molecules can produce positive ions, neutral fragments, and, with much lower probability, negative ions.

The role of negative-ion production has generally attracted little attention. For formic acid, a study by Guillemin et al. [7] reported negative ion yields (NIYs) at the C $1 s$ edge. They used a magnetic mass spectrometer to reveal four negative-ionic species, in addition to 21 positive ones. Their study, however, did not allow for a direct comparison of branching ratios between the fragments. NIYs at the $\mathrm{O} 1 s$ edge have been measured in photon-stimulated ion desorption from condensed formic acid [8], but to our knowledge not in the gas phase. Positive-ion creation, in contrast, has been measured at the $\mathrm{C} 1 s$ [7,9,10] and $\mathrm{O} 1 s$ [11] ionization edges. The deuterated versions of formic acid (DCOOH, HCOOD, and DCOOD) have also been the subject of fragmentation studies with positive-ion detection $[10,12]$. Fragmentation following VUV excitation was studied with photofragment fluorescence spectroscopy [13].

Our recent study on water in the gas phase showed that negative- and positive-ion coincidence spectroscopy can be a sensitive probe of weak features in the decay and fragmentation channels of small molecules [14]. Since production of negative ions necessarily must be accompanied by positive ions, it is desirable to detect them in coin- 
cidence. Most core-excited molecules relax by electronic emission. The net positive charge suggests that negative-ion production should be associated with either highly charged positive fragments or several singly charged fragments. A complete picture of the fragmentation patterns thus requires the ability to detect several positive ions in coincidence with a negative ion. In this paper, we will report on such fragmentation patterns involving three- and four-ionic fragments, namely, negative-ion/positive-ion/positive-ion coincidences (NIPIPICO) and negative-ion/positive-ion/positiveion/positive-ion coincidences (NIPIPIPICO).

\section{EXPERIMENT}

Experiments were performed at the high-resolution $\left(E / \Delta E>10^{4}\right)$ Gas Phase Photoemission beam line of the Elettra synchrotron radiation laboratory (Trieste, Italy) $[15,16]$.

An effusive jet of gaseous formic acid was let into a vacuum chamber through a gas needle controlled by a leak valve. The sample was purified from dissolved gases by repeated freeze-pump-thaw cycles. The vapor pressure of formic acid at ambient temperature was sufficient to drive a steady gas flow through the leak valve. The gas jet and the photon beam crossed in the center of the interaction region of the coincidence setup. The chamber pressure was kept at $6 \times 10^{-7} \mathrm{mbar}$, but it is estimated that the gas pressure was 10-50 times higher in the interaction region. The intensity of the light was monitored with a photodiode at the downstream exit of the chamber.

Our negative- and positive-ion coincidence setup has been described in detail before [17]. Briefly, it consists of two timeof-flight (TOF) spectrometers operating in tandem. Positive and negative fragments are separated by an electrostatic field, mass dispersed in flight tubes, and detected with two singleanode multichannel plate (MCP) detectors. Both spectrometers are installed with their axes at the magic angle (54.7 degrees) with respect to the electric vector of the linearly polarized incident radiation, ensuring that the detected intensity is independent of the angular anisotropy parameter [18]. A weak magnetic field in the negative-ion flight tube deflects electrons, preventing them from reaching the negative-ion detector. We made amendments to the spectrometer compared to our most recent publication [14]. The negative-ion detector was reinstalled with better electrical insulation, allowing us to put a higher attraction potential on the detector surface $(+2000$ $\mathrm{V}$, compared to $+900 \mathrm{~V}$ previously) and a higher gain potential over the double MCP stack (1850 V, compared to $1700 \mathrm{~V}$ previously). We could thereby run both TOF spectrometers with approximately twice the extraction potentials, increasing the collection efficiency of, in particular, the positive-ion TOF spectrometer. The cutoff kinetic energy for full detection was increased to $5.5 \mathrm{eV}$ in the positive-ion TOF spectrometer (previously $2 \mathrm{eV}$ ) [19]. This, in effect, allows for more efficient detection of fast $\mathrm{H}^{+}$ions.

Due to the single-anode readout of the positive-ion detector, the instrument cannot record ions separated by less than $10 \mathrm{~ns}$. This reduces the count rate of coincidence channels with two identical positive fragments, i.e., $\mathrm{O}^{-} / \mathrm{H}^{+} / \mathrm{H}^{+}$and $\mathrm{H}^{-} / \mathrm{O}^{+} / \mathrm{O}^{+}$. Their quantitative yield should thus not be directly compared to other channels.

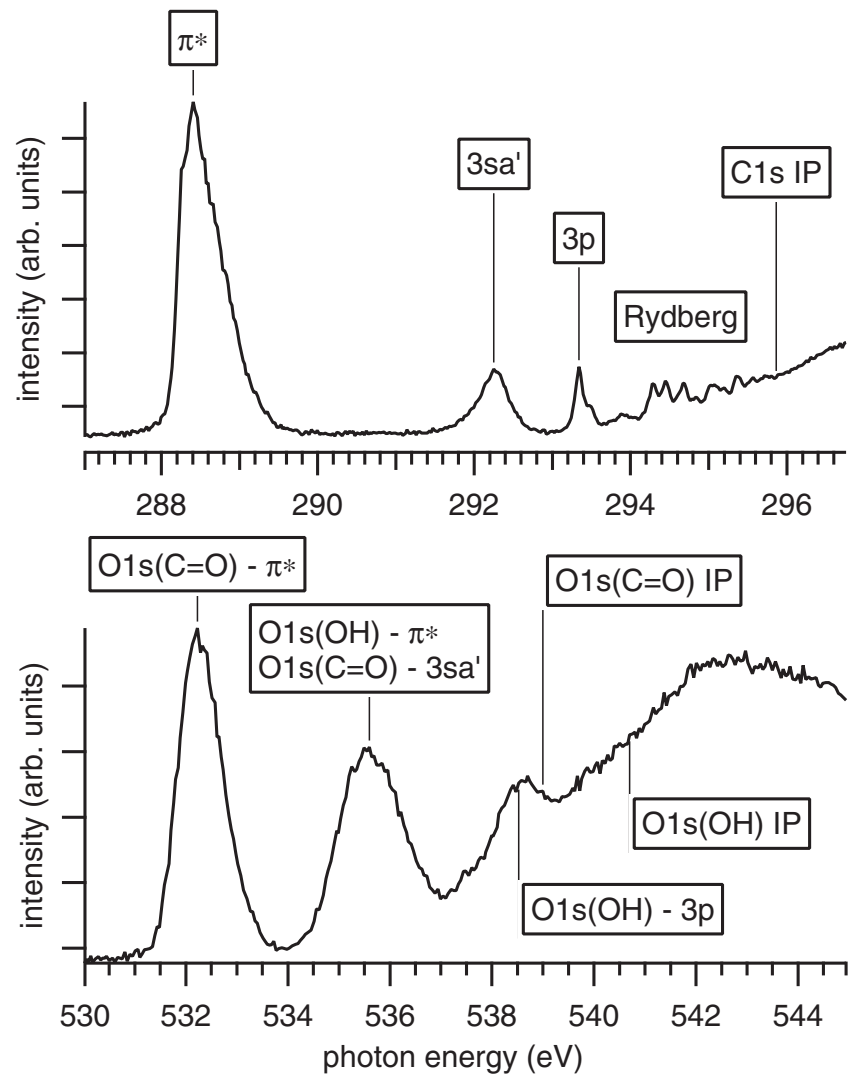

FIG. 1. Total positive-ion yields (TPIYs) at the $\mathrm{C} 1 \mathrm{~s}$ and $\mathrm{O} 1 \mathrm{~s}$ absorption edges with designations of resonant features [20].

Data was recorded while setting the photon energy at the known resonances and features in the near-edge x-ray absorption fine-structure (NEXAFS) spectrum. At the $\mathrm{C} 1 \mathrm{~s}$ and $\mathrm{O} 1 s$ edge, a negative-ion and/or positive-ion coincidence spectrum at each photon energy was measured for 60 and $80 \mathrm{~min}$, respectively. The positions of the resonances and features were determined from total positive-ion yields (TPIYs) measured by the same instrument, as displayed in Fig. 1. These resonant features have been studied earlier with near-edge X-ray absorption spectroscopy [20] and inner-shell electron energy loss spectroscopy [21,22].

The ground-state geometry of $\mathrm{HCOOH}$ is planar and has $C_{s}$ symmetry, and thus all orbitals have either $A^{\prime}$ or $A^{\prime \prime}$ symmetry [23]. Many previous works have identified the lower unoccupied orbitals as $\pi$ and $\sigma$ orbitals [11,20-22]. Others have considered $\mathrm{HCOOH}$ to belong to the $C_{1}$ symmetry group [7], and thus designated all orbitals as $A$. We will in this paper use the notation of Prince et al. [20], which is the most widespread; in particular, $\pi *$ for the lowest unoccupied molecular orbital (LUMO) and $3 s a^{\prime}$ for the LUMO +1 . These are otherwise designated as $13 A$ and $14 A$ in the $C_{1}$ symmetry, and should be designated $3 A^{\prime \prime}$ and $11 A^{\prime}$ in the $C_{s}$ symmetry. The $\pi^{*}$ orbital is mostly located at the $\mathrm{C}=\mathrm{O}$ group [22,24]. The $3 s a^{\prime}$ has been identified as an antibonding orbital in $\mathrm{OH}$ $[23,25]$. While the O $1 s$ TPIY only contains broad resonances, $\mathrm{C} 1 s$ TPIY shows a prominent set of Rydberg resonances above the $\pi^{*}$ and $3 s a^{\prime}$ peaks, leading up to the ionization potential (IP) [20]. A broad $\sigma^{*}$ resonance is visible in part 


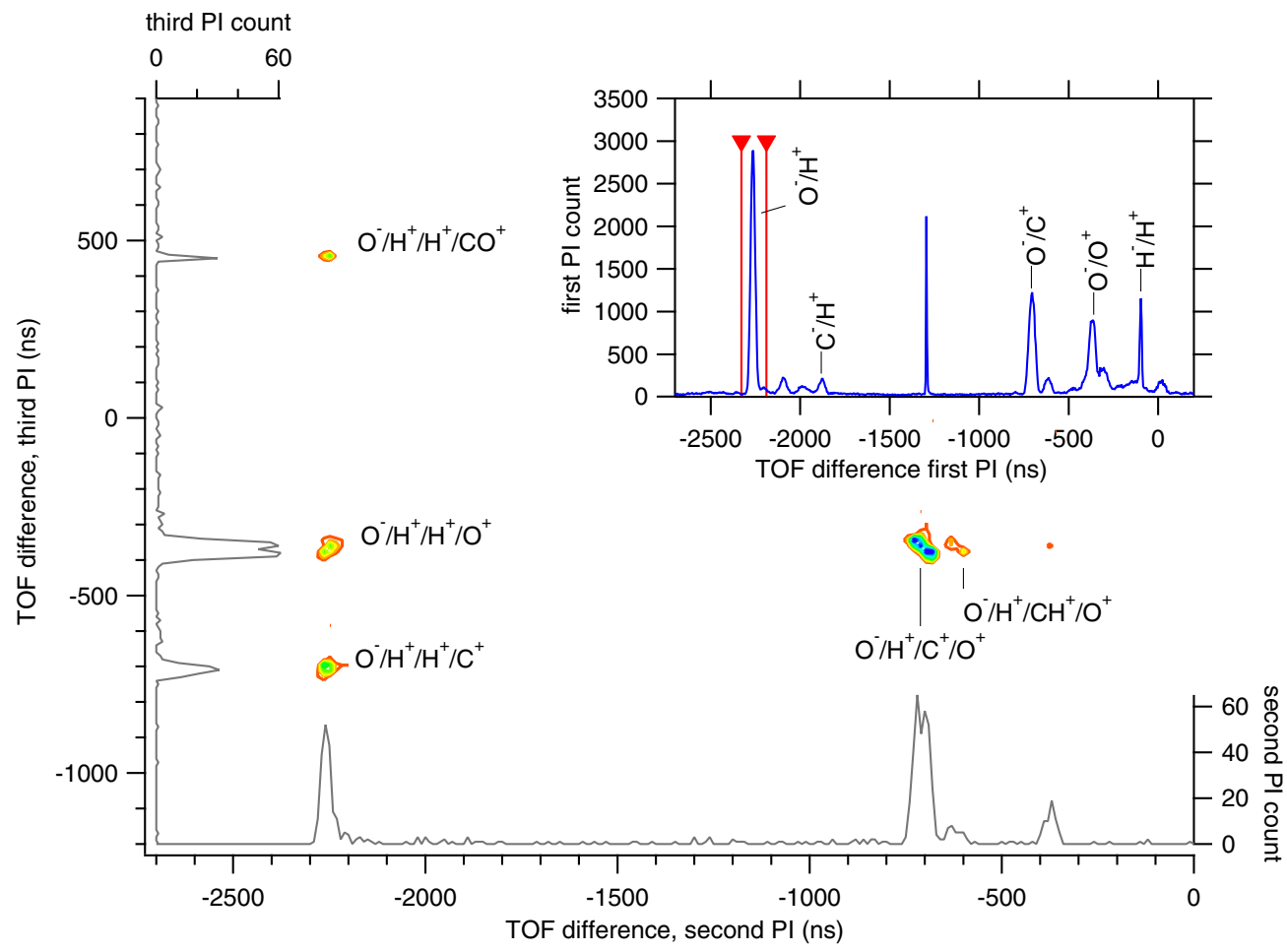

FIG. 2. Intensity map showing NIPIPIPICO events of type $\mathrm{O}^{-} / \mathrm{H}^{+} / \mathrm{PI}_{2} / \mathrm{PI}_{3}$, where $\mathrm{PI}_{2}$ and $\mathrm{PI}_{3}$ are two positive ions, measured at the Rydberg resonances close to the $\mathrm{C} 1 s$ edge. To increase clarity, we have included all data from the measurements performed in the photon-energy range 293.3-295.4 eV (see Fig. 3). From the events in the two-ion NIPI ${ }_{1} \mathrm{CO}$ spectrum (inset), we select the $\mathrm{O}^{-} / \mathrm{H}^{+}$peak, and plot a contour map of all $\mathrm{PI}_{2}$ and $\mathrm{PI}_{3}$ that have been detected in coincidence with this ion pair. Each island in the map corresponds to a four-body coincidence channel. The TOF differences of the first, second, and third PI are calculated relative to the arrival of the negative ion.

above IP. The O $1 s$ TPIY contains contributions from both constituent $\mathrm{O}$ atoms. The $\mathrm{O} 1 s(\mathrm{OH}) \rightarrow \pi *$ resonance is believed to overlap with $\mathrm{O} 1 s(\mathrm{C}=\mathrm{O}) \rightarrow 3 s a^{\prime}[21,22]$.

\section{DATA ANALYSIS}

Time stamps for detected ions at the two detectors were recorded in separate data libraries. A positive ion was considered coincident if it was detected within $3000 \mathrm{~ns}$ before or $5000 \mathrm{~ns}$ after a negative ion. If two or three positive ions arrived within this window, a three-body or four-body coincidence event was recorded. Only the difference in flight time between a negative and a positive fragment was established in the data analysis. The identity of peaks in the arrival-time difference spectrum, corresponding to pairs of one negative and one positive ion, was determined from electrostatic simulations and acquisition of photoelectron and positive-ion coincidence spectra, as described in our previous publications [14,17]. The NIPIPIPICO map in Fig. 2 illustrates how four-body channels were identified from arrival-time difference spectra.

All measured data were normalized to the intensity of the light such that one coincidence event equals between 0.9 and 1.4 arb. units, as they are presented in the figures and tables.

\section{RESULTS AND DISCUSSION}

The dominant decay channel for core-excited $\mathrm{HCOOH}$ below threshold is emission of a resonant Auger electron. Production of a singly charged negative fragment from the dissociation process leaves the remaining fragments with a net charge of +2 . If the doubly charged fragment is not a single atom, it likely dissociates further into two singly charged fragments:

$$
\begin{aligned}
h v+\mathrm{ABC} & \rightarrow \mathrm{ABC}^{* *} \rightarrow \mathrm{ABC}^{+*}+e_{\text {Auger }}^{-} \\
\mathrm{ABC}^{+*} & \rightarrow \mathrm{A}^{-}+\mathrm{B}^{+}+\mathrm{C}^{+},
\end{aligned}
$$

where $\mathrm{A}, \mathrm{B}$, and $\mathrm{C}$ are atoms or small molecular fragments, ** denotes a core-excited species, and $*$ denotes a valence-excited species.

We can identify four negative ion species at the $\mathrm{C}$ and $\mathrm{O}$ edges: $\mathrm{H}^{-}, \mathrm{C}^{-}, \mathrm{O}^{-}$, and $\mathrm{OH}^{-}$. The same species have previously been observed at the $\mathrm{C} 1 s$ edge [7]. $\mathrm{O}^{-}$channels are dominating, followed by $\mathrm{H}^{-}$and $\mathrm{C}^{-}$. The $\mathrm{OH}^{-}$channels are very weak and can only be distinguished at a few strong resonances. Counting the individual yields, we identify 21 three-body channels and 5 four-body channels with statistical significance. No five-body coincidences have been observed.

\section{A. Three-body coincidences at the $\mathrm{C} 1 s$ edge}

Figure 3 shows the total NIPIPICO yield and the branching ratios of all three-body coincidence channels involving $\mathrm{O}^{-}$, $\mathrm{H}^{-}$, and $\mathrm{C}^{-}$ions at the $\mathrm{C} 1 s$ edge. Figure 3(a) displays the total NIPIPICO yield as the sum of all individual NIPIPICO channels. In comparison to the TPIY, the total NIPIPICO yield is much enhanced at the Rydberg resonances and grows as the IP is approached. A comparison with noncoincident NIYs measured by Guillemin et al. [7] confirms 


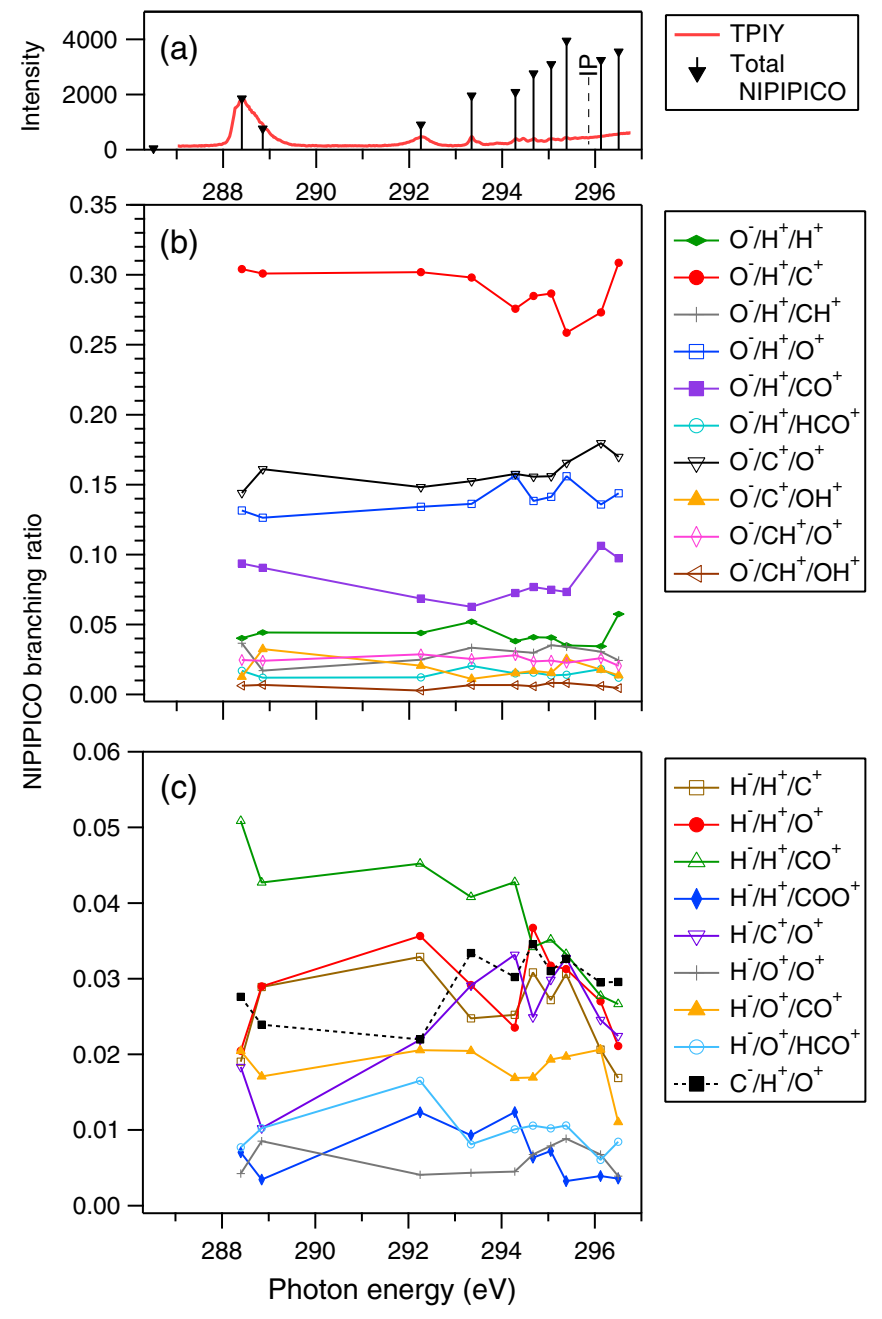

FIG. 3. Negative-ion/positive-ion/positive-ion coincidences at the $\mathrm{C} 1 s$ edge. (a) Total NIPIPICO yield, i.e., the sum of all counts in the coincidences channels, and total positive-ion yield (TPIY). The two yields are scaled to the same height at the $\pi^{*}$ resonance. (b) The branching ratios of the NIPIPICO channels with $\mathrm{NI}=\mathrm{O}^{-}$. (c) The branching ratios of the NIPIPICO channels with $\mathrm{NI}=\mathrm{H}^{-}$and $\mathrm{C}^{-}$. The energy point at $286.5 \mathrm{eV}$ has been omitted in (b) and (c) due to insufficient statistics.

that negative-ion production increases as the photon energy is tuned to high-Rydberg resonances, peaking just below the IP. However, in their study, the NIYs at Rydberg resonances are lower than at the $\pi^{*}$ resonance. Above IP, the NIYs have exponential decays, attributed to postcollision interaction (PCI), where a slow photoelectron is overtaken by a fast Auger electron and subsequently recaptured when it becomes exposed to the molecule's doubly charged core. Similar behavior has been observed for several small molecules [26-29].

Figures 3(b) and 3(c) shows branching ratios for all NIPIPICO channels except for two weak channels involving the $\mathrm{OH}^{-}$ion $\left(\mathrm{OH}^{-} / \mathrm{H}^{+} / \mathrm{C}^{+}\right.$and $\left.\mathrm{OH}^{-} / \mathrm{H}^{+} / \mathrm{O}^{+}\right)$. Branching ratios are extracted as the fraction of the total NIPIPICO yield, obtained as a sum of all individual NIPIPICO channels. No channels involving doubly charged positive ions were observed either in two-body NIPICO yields or in three-body NIPIPICO yields. The positive charge is thus preferentially distributed over several fragments. Tables with normalized intensities for all channels are provided as Supplemental Material [30].

$\mathrm{O}^{-}$production accounts for more than $80 \%$ of the total NIPIPICO yield. It is dominated by channels that suggest a complete fragmentation of the $\mathrm{HCOOH}$ molecule: $\mathrm{O}^{-} / \mathrm{H}^{+} / \mathrm{C}^{+}$, $\mathrm{O}^{-} / \mathrm{C}^{+} / \mathrm{O}^{+}$, and $\mathrm{O}^{-} / \mathrm{H}^{+} / \mathrm{O}^{+}$. The branching ratios of these channels change by only a few percent across the different $\mathrm{C}$ $1 s$ excitations and the $\mathrm{C} 1 s$ ionization potential. It is, however, interesting to note that the branching ratios of $\mathrm{O}^{-} / \mathrm{H}^{+} / \mathrm{C}^{+}$and $\mathrm{O}^{-} / \mathrm{H}^{+} / \mathrm{O}^{+}$are, in general, mirror images of each other. The same applies to the $\mathrm{O}^{-} / \mathrm{H}^{+} / \mathrm{H}^{+}$and $\mathrm{O}^{-} / \mathrm{H}^{+} / \mathrm{CO}^{+}$channels. Both of the observations could imply that the $\mathrm{O}^{-} / \mathrm{H}^{+}$pair in these NIPIPICO channels mostly originates from the hydroxyl group $(\mathrm{OH})$ of the molecule, while the other positive ion results from a further breakage of the $\mathrm{CO}^{+}$or $\mathrm{HCO}^{+}$units. Channels where parts of the $\mathrm{O}=\mathrm{C}-\mathrm{O}$ molecular framework remain intact are scarce; the strongest of them is $\mathrm{O}^{-} / \mathrm{H}^{+} / \mathrm{CO}^{+}$. The $\mathrm{O}^{-} / \mathrm{H}^{+} / \mathrm{H}^{+}$channel is, in reality, more intense than what appears in the figure because of the experimental difficulty to observe two protons that arrive close in time. Only one $\mathrm{C}^{-}$ channel is distinguishable: $\mathrm{C}^{-} / \mathrm{H}^{+} / \mathrm{O}^{+}$has its peak branching ratio at the Rydberg resonances, while it is slightly lower at the $\pi^{*}$ resonance. The $\mathrm{C}^{-}$channel necessarily means a complete fragmentation of the $\mathrm{O}=\mathrm{C}-\mathrm{O}$ framework.

The branching ratios of the NIPIPICO channels involving the $\mathrm{H}^{-}$ion do not show conclusive changes in the $\mathrm{C} 1 \mathrm{~s}$ coreexcitation region-they are within statistical uncertainty of $\sim \pm 0.5 \%$ of the data points-but they seem to decrease in general when the $\mathrm{C} 1 \mathrm{~s}$ threshold is crossed. Adding up the individual channels, we find that the $\mathrm{H}^{-}$production is largest at the $\mathrm{C} 1 s \rightarrow 3 s a^{\prime}$ resonance with the branching ratio of $19 \%$, an increase of $4 \%$ from the $\mathrm{C} 1 s \rightarrow \pi^{*}(\mathrm{CO})$ resonance. The higher abundance of $\mathrm{H}^{-}$at the $\mathrm{C} 1 s \rightarrow 3 s a^{\prime}$ resonance has previously been proposed to hint at a $\mathrm{C}-\mathrm{H}$ breaking process with the charge localizing on the $\mathrm{H}$ fragment [7]. To assess this hypothesis, it is relevant to consider $\mathrm{H}^{-}$in coincidence with $\mathrm{CH}^{+}$. Unfortunately, $\mathrm{H}^{-}$in coincidence with $\mathrm{CH}^{+}$or $\mathrm{OH}^{+}$ as separate channels are below the detection limit. However, a summation of all data at the $\mathrm{C} 1 s$ edge shows evidence of weak $\mathrm{H}^{-} / \mathrm{CH}^{+} / \mathrm{O}^{+}$and $\mathrm{H}^{-} / \mathrm{C}^{+} / \mathrm{OH}^{+}$channels, with the latter stronger than the former. This implies that both $\mathrm{H}$ atoms can hold negative charge, but neither confirms nor disproves the suggestion by Guillemin et al. that the $\mathrm{H}$ in the $\mathrm{C}-\mathrm{H}$ group is preferred for negative-ion production.

One of the measurements was performed at the high vibrational levels of the $\mathrm{C} 1 s \rightarrow \pi^{*}(\mathrm{CO})$ excitation. It shows that the branching ratios of the $\mathrm{O}^{-} / \mathrm{C}^{+} / \mathrm{O}^{+}$and $\mathrm{O}^{-} / \mathrm{C}^{+} / \mathrm{OH}^{+}$ channels increased when compared to the spectrum taken at the maximum of the $\mathrm{C} 1 s \rightarrow \pi^{*}(\mathrm{CO})$ resonance. The latter channel is likely coupled with the ejection of $\mathrm{O}^{-}$from the $\mathrm{C}=\mathrm{O}$ unit, whereas the origin of $\mathrm{O}^{-}$cannot be deduced in the case of the $\mathrm{O}^{-} / \mathrm{C}^{+} / \mathrm{O}^{+}$channel. The branching ratio of the $\mathrm{O}^{-} / \mathrm{H}^{+} / \mathrm{CH}^{+}$clearly went down with the increase of the vibrational energy in this core-excited state, indicating that less $\mathrm{O}^{-} / \mathrm{H}^{+}$ion pairs are produced (from the hydroxyl group). In summary, the behavior of the NIPIPICO channels at the $\mathrm{C} 1 s \rightarrow \pi^{*}(\mathrm{CO})$ resonance hints that $\mathrm{O}^{-}$ejection from the $\mathrm{C}=\mathrm{O}$ site becomes more favored when the vibrational excitation increases. 

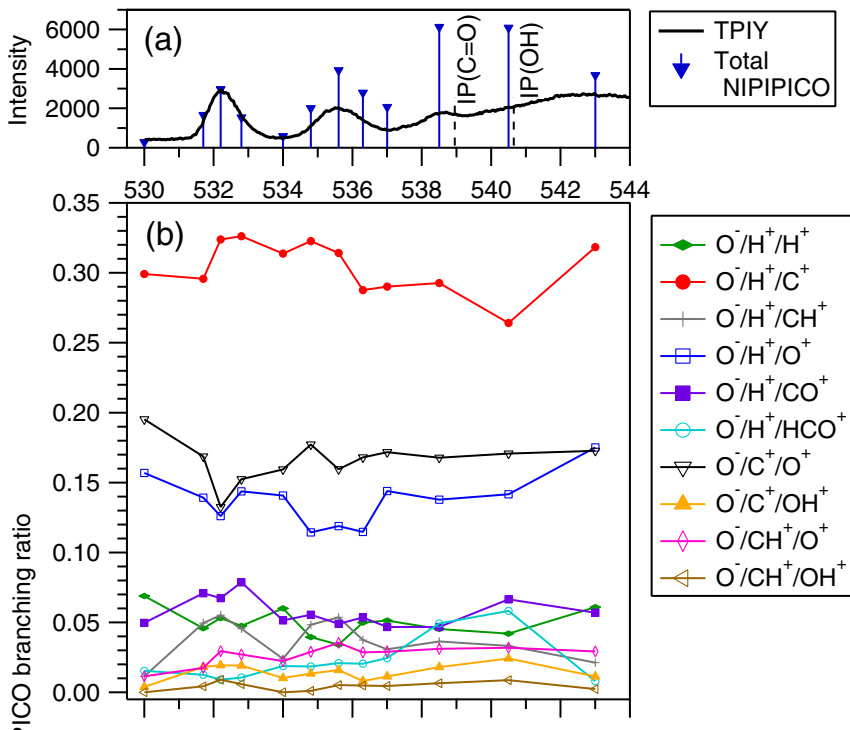

흘

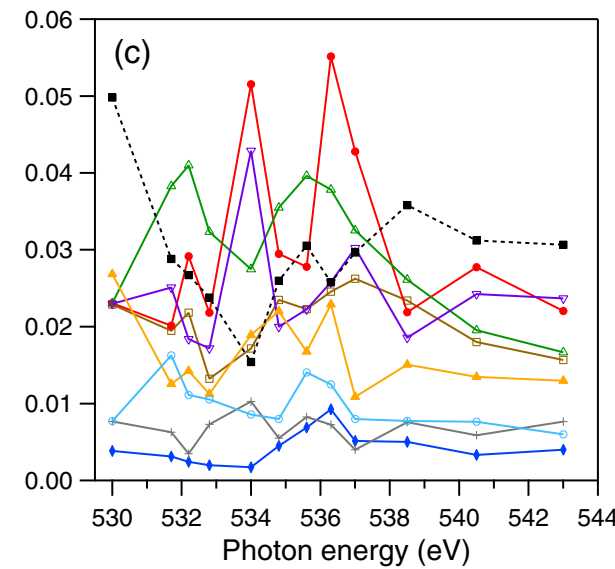

FIG. 4. Negative-ion/positive-ion/positive-ion coincidences at the $\mathrm{O} 1 s$ edge. See Fig. 3 caption for details.

\section{B. Three-body coincidences at the $O 1 s$ edge}

NIPIPICO branching ratios and the total NIPIPICO yield at the $\mathrm{O} 1 s$ edge are given in Fig. 4. Also at this edge, the total coincidence yield increases as the two IPs are approached. The high yield at IP and decrease at higher photon energies is consistent with the PCI recapture process that has been observed for other molecules. The yield above IP has a significant drop, which resembles how negative-ion production drops above IP in many small molecules (see above). NIYs at the $\mathrm{O} 1 s$ edge of $\mathrm{HCOOH}$ have to our knowledge not been published. The same $\mathrm{O}^{-}$NIPIPICO channels are most intense at the $\mathrm{O} 1 s$ edge as at the $\mathrm{C} 1 s$ edge and their branching ratios are quite similar. The behavior of the $\mathrm{O}^{-} / \mathrm{H}^{+} / \mathrm{C}^{+}$and $\mathrm{O}^{-} / \mathrm{H}^{+} / \mathrm{O}^{+}$channels is less mirrorlike at the $\mathrm{O} 1 s$ edge than at the $\mathrm{C} 1 s$ edge, but some of it is still visible. The $\mathrm{O}^{-}$channels that are relatively most enhanced at the first $\mathrm{O} 1 s$ resonance, $\mathrm{O} 1 s(\mathrm{C}=\mathrm{O}) \rightarrow \pi^{*}$, are $\mathrm{O}^{-} / \mathrm{H}^{+} / \mathrm{CH}^{+}$and $\mathrm{O}^{-} / \mathrm{H}^{+} / \mathrm{CO}^{+}$, which again point to the hydroxyl group as the source of the $\mathrm{O}^{-} / \mathrm{H}^{+}$ pair. The $\mathrm{O}^{-} / \mathrm{H}^{+} / \mathrm{CH}^{+}$peaks also at the second $\mathrm{O} 1 s$ resonance around $535.5 \mathrm{eV}$. The four strongest $\mathrm{O}^{-}$NIPIPICO channels increase at the high-energy side of the $\mathrm{O} 1 s(\mathrm{C}=\mathrm{O}) \rightarrow \pi^{*}$ resonance, where the vibrational excitation of the core-excited

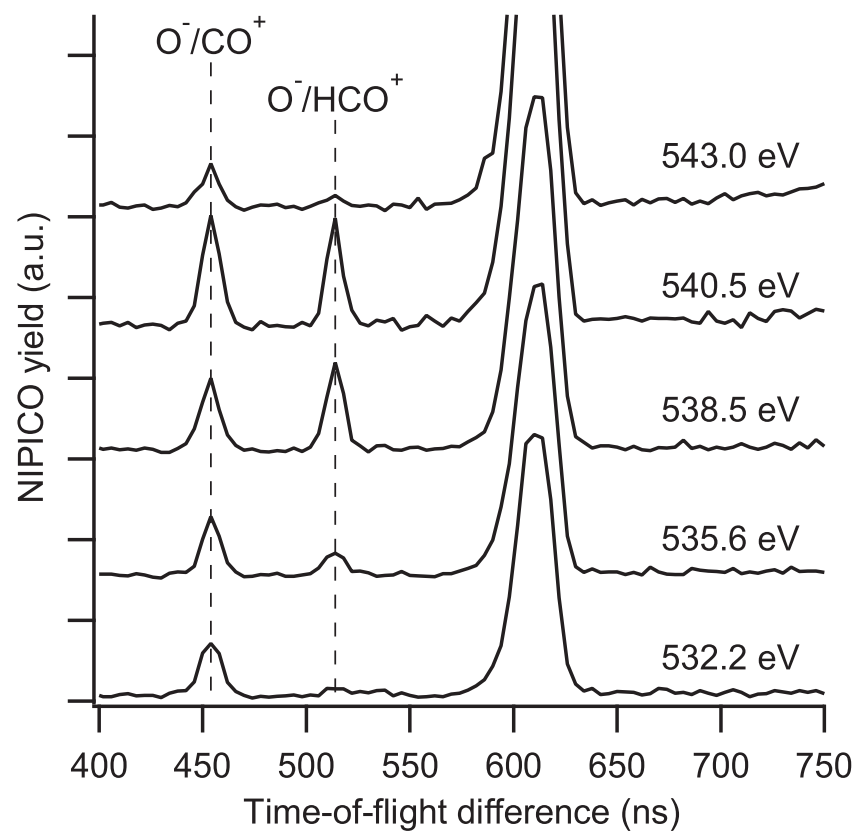

FIG. 5. Extract of the TOF difference spectrum indicating the $\mathrm{O}^{-} / \mathrm{CO}^{+}$and $\mathrm{O}^{-} / \mathrm{HCO}^{+}$peaks for five selected photon energies at the $\mathrm{O} 1 \mathrm{~s}$ edge. The data for each energy were measured for $80 \mathrm{~min}$ and normalized to the intensity of the photon beam. The larger peak at $620 \mathrm{~ns}$ is a PEPICO channel arising from nonfiltered electrons. The evolution of the $\mathrm{O}^{-} / \mathrm{HCO}^{+}$channel differs clearly from that of $\mathrm{O}^{-} / \mathrm{CO}^{+}$.

state is largest. In contrast, the branching ratios of the $\mathrm{H}^{-}$ NIPIPICO channels decrease when compared to the ratios determined at the resonance energy.

The only $\mathrm{C}^{-}$channel, $\mathrm{C}^{-} / \mathrm{H}^{+} / \mathrm{O}^{+}$, has a rather constant branching ratio of about $3 \%$ at $\mathrm{O} 1 s$ excitations.

The minority channel $\mathrm{O}^{-} / \mathrm{H}^{+} / \mathrm{HCO}^{+}$has a peculiar behavior at the $\mathrm{O} 1 s$ edge. We observe that this channel has a larger relative increase than any other channel as the IP is approached (Fig. 4). We demonstrate that the observed behavior is statistically significant by showing the $\mathrm{O}^{-} / \mathrm{HCO}^{+}$ two-ion coincidence spectra at certain photon energies in Fig. 5. $\mathrm{O}^{-} / \mathrm{HCO}^{+}$and $\mathrm{O}^{-} / \mathrm{CO}^{+}$have the same ratio at the $3 p$ resonance $(538.5 \mathrm{eV})$ and just above the first IP, while $\mathrm{O}^{-} / \mathrm{HCO}^{+}$is depressed both above and below these resonances; in particular at the $\mathrm{O} 1 s(\mathrm{C}=\mathrm{O}) \rightarrow \pi^{*}$ resonance, the $\mathrm{O}^{-} / \mathrm{HCO}^{+}$yield is barely detectable. PIY measurements do not explain this behavior; $\mathrm{HCO}^{+}$and $\mathrm{CO}^{+}$are produced at similar rates at $\mathrm{O} 1 s(\mathrm{C}=\mathrm{O}) \rightarrow \pi^{*}$, while the $\mathrm{HCO}^{+}$is suppressed to half of the $\mathrm{CO}^{+}$yield at the second resonance [11]. The same study shows an increase of noncoincident $\mathrm{HCO}^{+}$production above IP, remaining firmly below the $\mathrm{CO}^{+}$ yield. PIY measurements of formic acid with a deuturated hydroxyl group (HCOOD) showed that $\mathrm{HCO}^{+}$has a much higher yield than $\mathrm{DCO}^{+}$at the $\mathrm{O} 1 s$ edge [11], which suggests that noncoincident $\mathrm{HCO}^{+}$in $\mathrm{HCOOH}$ preferably originates from breakage of the $\mathrm{C}-\mathrm{OH}$ bond.

The only possible route to $\mathrm{O}^{-} / \mathrm{H}^{+} / \mathrm{HCO}^{+}$after resonant Auger decay is

$$
\begin{aligned}
h v+\mathrm{HCOOH} & \rightarrow \mathrm{HCOOH}^{* *} \rightarrow \mathrm{HCOOH}^{+*}+e_{\text {Auger }}^{-} \\
\mathrm{HCOOH}^{+*} & \rightarrow \mathrm{O}^{-}+\mathrm{HCO}^{+}+\mathrm{H}^{+} .
\end{aligned}
$$



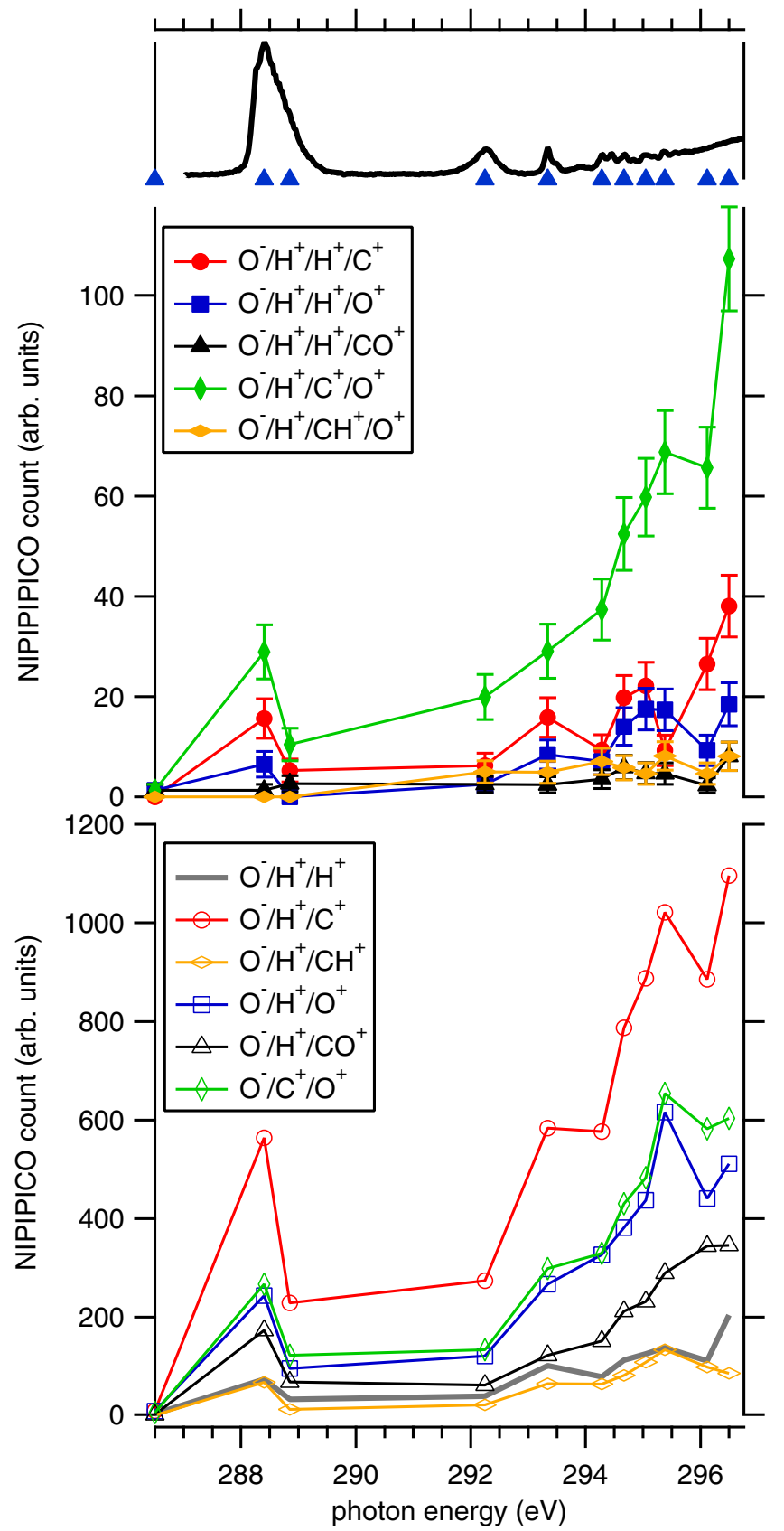

FIG. 6. Top panel: TPIY at the C $1 s$ IP. Blue triangles indicate the measured photon-energy positions. Middle panel: Yields of the five observed four-body coincidence channels. Bottom panel: Selected three-body coincidence channels for comparisons. All yields are normalized using the same normalization factors.

$\mathrm{O}^{-} / \mathrm{H}^{+} / \mathrm{CO}^{+}$has a similar production mechanism,

$$
\mathrm{HCOOH}^{+(+) *} \rightarrow \mathrm{O}^{-}+\mathrm{CO}^{+}+\mathrm{H}^{+}+\mathrm{H}^{(+)},
$$

with only one additional broken bond. (Creation of an $\mathrm{H}_{2}{ }^{+}$ ion is possible, but not probable.) If, as suggested above, the hydroxyl group is the primary source for $\mathrm{O}^{-} / \mathrm{H}^{+}$, these yields suggest that the $\mathrm{C}-\mathrm{H}$ bond is significantly less likely to break at resonances where $\mathrm{O}^{-} / \mathrm{H}^{+} / \mathrm{HCO}^{+}$is observed.

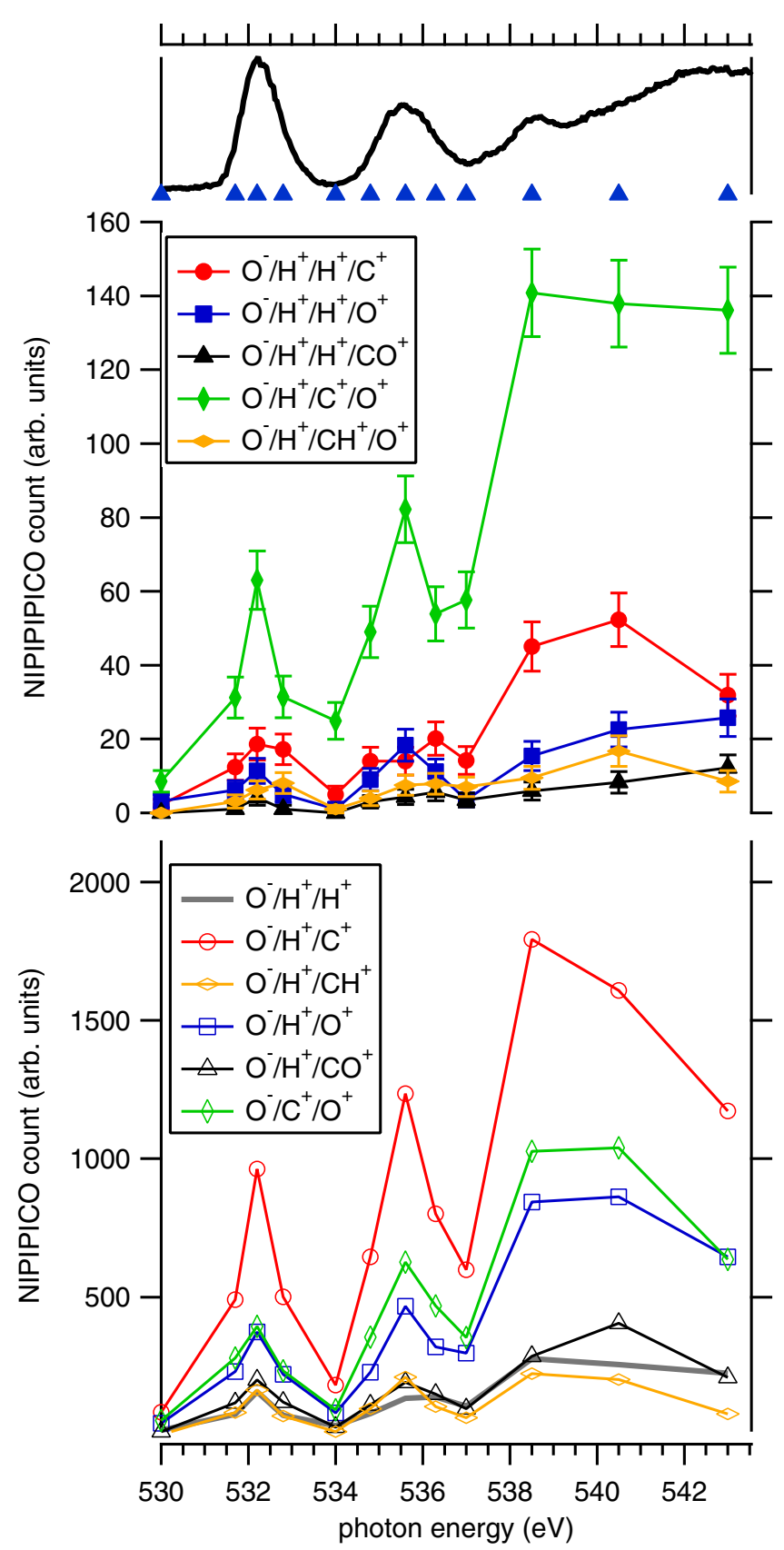

FIG. 7. Total positive-ion, NIPIPIPICO, and selected NIPIPICO yields at the $\mathrm{O} 1 s$ edge. See Fig. 6 caption for details.

\section{Four-body coincidences}

Yields for the statistically significant four-body coincidence channels (NIPIPIPICO) are shown in Figs. 6 and 7, together with a selection of three-body coincidence spectra for reference purposes. We have only observed channels including the $\mathrm{O}^{-} / \mathrm{H}^{+}$pair. All yields containing the $\mathrm{H}^{+} / \mathrm{H}^{+}$pair are expected to be under-represented with respect to the $\mathrm{O}^{-} / \mathrm{H}^{+} / \mathrm{C}^{+} / \mathrm{O}^{+}$ and $\mathrm{O}^{-} / \mathrm{H}^{+} / \mathrm{CH}^{+} / \mathrm{O}^{+}$channels because of the experimental difficulty to observe two protons that arrive close in time.

The channels where all created fragments are recorded, $\mathrm{O}^{-} / \mathrm{H}^{+} / \mathrm{H}^{+} / \mathrm{CO}^{+}$and $\mathrm{O}^{-} / \mathrm{H}^{+} / \mathrm{CH}^{+} / \mathrm{O}^{+}$, are weak, indicating that a complete fragmentation of the molecule dominates. Due to the small yields and the expected $\mathrm{H}^{+} / \mathrm{H}^{+}$suppression, it is 
not possible to assess which of the two complete fragmentation patterns is stronger.

The ions recorded as four-body coincidences in this study carry a net charge of +2 , since we have only observed singly charged fragments. Above threshold, such channels are expected, following normal Auger decay,

$$
\begin{aligned}
h v+\mathrm{ABCD} & \rightarrow \mathrm{ABCD}^{+* *}+e_{\mathrm{ph}}^{-} \\
\mathrm{ABCD}^{+* *} & \rightarrow \mathrm{ABCD}^{++*}+e_{\text {Auger }}^{-} \\
\mathrm{ABCD}^{++*} & \rightarrow \mathrm{A}^{-}+\mathrm{B}^{+}+\mathrm{C}^{+}+\mathrm{D}^{+} .
\end{aligned}
$$

Below threshold, such fragmentation can occur after resonant double Auger decay, where a core-excited state decays by simultaneously emitting two electrons which share the available energy. For high core-to-Rydberg excitations, doubly ionized final states can also be produced in sequential decay, where final states of resonant Auger decay autoionize. The prominence of NIPIPIPICO close to the $\mathrm{C} 1 s$ and $\mathrm{O} 1 s$ ionization potentials could be explained by such decay. The opening of the normal Auger decay channel above IP explains well the high abundance there.

\section{CONCLUSION}

We have studied the negative-ion fragment formation of formic acid at its core edges by means of three- and four-body ion coincidence spectroscopy. $\mathrm{O}^{-}$is the most prominent negative fragment, followed by $\mathrm{H}^{-}, \mathrm{C}^{-}$, and $\mathrm{OH}^{-}$. If a negative ion is released, the molecule has a strong preference for complete fragmentation. The three most prominent NIPIPICO channels, $\mathrm{O}^{-} / \mathrm{H}^{+} / \mathrm{C}^{+}, \mathrm{O}^{-} / \mathrm{C}^{+} / \mathrm{O}^{+}$, and $\mathrm{O}^{-} / \mathrm{H}^{+} / \mathrm{O}^{+}$, bear direct evidence of fragmentation where all bonds in the $\mathrm{O}=\mathrm{C}-\mathrm{O}$ framework are broken, whereas the channels where one or both of the bonds in this framework remain intact are minor. Two pairs of NIPIPICO channels involving the $\mathrm{O}^{-} / \mathrm{H}^{+}$ion pair displayed quite mirrorlike trends in their branching ratios, especially at the $\mathrm{C} 1 s$ edge, hinting that the hydroxyl group is the predominant source of $\mathrm{O}^{-}$ions. Detection of fourbody coincidences shows that negative ions can be produced even in processes where the accompanying fragments have a combined positive net charge of +2 , evidencing a strong charge redistribution in the molecule. Doubly charged positive ions were not observed in any fragmentation processes that yield negative ions. Branching ratios of individual fragmentation channels typically vary by a couple of percent among resonances below a given core IP, with the striking exception of an (almost) complete suppression of the $\mathrm{O}^{-} / \mathrm{H}^{+} / \mathrm{HCO}^{+}$ coincidence channel at the $\mathrm{O} 1 s(\mathrm{C}=\mathrm{O}) \rightarrow \pi^{*}$ resonance. A more complete understanding of these elaborate fragmentation paths requires a deeper theoretical understanding of the negative-ion producing dynamics. Further studies in this field should involve theoretical investigation of the electronic processes governing negative-ion creation at core edges.

\section{ACKNOWLEDGMENTS}

The authors thank E. S. El Afifi and L. Christiansson, MAX IV Laboratory, for their help with the design and construction of the instrument upgrade. M. Odelius contributed with fruitful discussions. We acknowledge Elettra-Sincrotrone Trieste for providing beam time (Proposal No. 20150229) and the staff at Elettra for their kind assistance.
[1] A. Chebbi and P. Carlier, Atmos. Environ. 30, 4233 (1996).

[2] W. Leitner, Angew. Chem. 34, 2207 (1995).

[3] C. Rice, S. Ha, R. Masel, P. Waszczuk, A. Wieckowski, and T. Barnard, J. Power Sources 111, 83 (2002).

[4] X. Yu and P. G. Pickup, J. Power Sources 182, 124 (2008).

[5] S. Moret, P. J. Dyson, and G. Laurenczy, Nat. Commun. 5, 4017 (2014).

[6] S.-Y. Liu, J. M. Girart, A. Remijan, and L. E. Snyder, Astrophys. J. 576, 255 (2002).

[7] R. Guillemin, W. C. Stolte, and D. W. Lindle, J. Phys. B: At., Mol. Opt. Phys. 42, 125101 (2009).

[8] D. Andrade, H. Boechat-Roberty, S. Pilling, E. da Silveira, and M. Rocco, Surf. Sci. 603, 3301 (2009).

[9] H. M. Boechat-Roberty, S. Pilling, and A. C. F. Santos, Astron. Astrophys. 438, 915 (2005).

[10] A. Guerra, J. Maciel, C. Turci, H. Ikeura-Sekiguchi, and A. Hitchcock, Chem. Phys. 326, 589 (2006).

[11] K. Tabayashi, K. Yamamoto, O. Takahashi, Y. Tamenori, J. R. Harries, T. Gejo, M. Iseda, T. Tamura, K. Honma, I. H. Suzuki, S. Nagaoka, and T. Ibuki, J. Chem. Phys. 125, 194307 (2006).

[12] M. S. Arruda, A. Medina, J. N. Sousa, L. A. V. Mendes, R. R. T. Marinho, and F. V. Prudente, J. Phys. Chem. A 120, 5325 (2016)
[13] M. Schwell, F. Dulieu, H.-W. Jochims, J.-H. Fillion, J.-L. Lemaire, H. Baumgärtel, and S. Leach, J. Phys. Chem. A 106, 10908 (2002).

[14] C. Stråhlman, A. Kivimäki, R. Richter, and R. Sankari, J. Phys. Chem. A 120, 6389 (2016).

[15] K. C. Prince, R. R. Blyth, R. Delaunay, M. Zitnik, J. Krempasky, J. Slezak, R. Camilloni, L. Avaldi, M. Coreno, G. Stefani, C. Furlani, M. de Simone, and S. Stranges, J. Synchrotron Rad. 5, 565 (1998).

[16] R. Blyth, R. Delaunay, M. Zitnik, J. Krempasky, R. Krempaska, J. Slezak, K. Prince, R. Richter, M. Vondracek, R. Camilloni, L. Avaldi, M. Coreno, G. Stefani, C. Furlani, M. de Simone, S. Stranges, and M.-Y. Adam, J. Electron Spectrosc. Relat. Phenom. 101-103, 959 (1999).

[17] C. Stråhlman, R. Sankari, A. Kivimäki, R. Richter, M. Coreno, and R. Nyholm, Rev. Sci. Instrum. 87, 013109 (2016).

[18] P. Morin, I. Nenner, P. M. Guyion, O. Dutuit, and K. Ito, J. Chim. Phys. 77, 605 (1980).

[19] C. Stråhlman, Ph. D. thesis, MAX IV Laboratory, Lund University, Sweden, 2016, http://lup.lub.lu.se/record/8866027.

[20] K. C. Prince, R. Richter, M. de Simone, M. Alagia, and M. Coreno, J. Phys. Chem. A 107, 1955 (2003).

[21] I. Ishii and A. P. Hitchcock, J. Chem. Phys. 87, 830 (1987).

[22] I. Ishii and A. Hitchcook, J. Electron Spectrosc. Relat. Phenom. 46, 55 (1988). 
[23] S. Leach, M. Schwell, D. Talbi, G. Berthier, K. Hottmann, H.-W. Jochims, and H. Baumgärtel, Chem. Phys. 286, 15 (2003).

[24] U. Hergenhahn, A. Rüdel, K. Maier, A. Bradshaw, R. Fink, and A. Wen, Chem. Phys. 289, 57 (2003).

[25] S. Leach, M. Schwell, F. Dulieu, J.-L. Chotin, H.-W. Jochims, and H. Baumgärtel, Phys. Chem. Chem. Phys. 4, 5025 (2002).

[26] G. Öhrwall, M. M. Sant'Anna, W. C. Stolte, I. DominguezLopez, L. T. N. Dang, A. S. Schlachter, and D. W. Lindle, J. Phys. B: At., Mol. Opt. Phys. 35, 4543 (2002).
[27] M. N. Piancastelli, R. Guillemin, W. C. Stolte, D. Ceolin, and D. W. Lindle, J. Electron Spectrosc. Relat. Phenom. 155, 86 (2007).

[28] W. C. Stolte, G. Öhrwall, M. M. Sant'Anna, I. D. Lopez, L. T. N. Dang, M. N. Piancastelli, and D. W. Lindle, J. Phys. B: At. Mol. Opt. Phys. 35, L253 (2002).

[29] W. C. Stolte, M. M. Sant'Anna, G. Öhrwall, I. DominguezLopez, M. N. Piancastelli, and D. W. Lindle, Phys. Rev. A 68, 022701 (2003).

[30] See Supplemental Material at http://link.aps.org/supplemental/ 10.1103/PhysRevA.96.023409 for tabulated normalized intensities for all three- and four-body fragmentation channels. 